\title{
Democracia y políticas públicas. El contorno de sus relaciones
}

Democracy and public policies. An outline of their relationship

Rodolfo Canto Sáenz

Universidad Autónoma de Yucatán

rodolfo.canto@uady.mx

Fecha de recepción

30.10.13

Fecha de aceptación 12.3.14

\section{Resumen}

Frente a los modelos de gobernanza sociopolítica, hoy en boga en América Latina, el artículo propone volver la vista a la arena política tradicional. Con base en la distinción analítica de Touraine entre Estado, sociedad civil y sociedad política, se aborda la relación entre democracia y políticas públicas, distinguiendo entre diversas formas de participación de los actores sociales y políticos. En América Latina, la región más desigual del mundo, la democracia sólo puede ser social. La lucha por las reivindicaciones democráticas siempre es posible $\mathrm{y}$, si logra fortalecer lo necesario a los movimientos sociales, grupos comunitarios y nuevos sujetos sociales, puede cambiar la correlación de fuerzas en determinadas áreas de la política pública en favor de intereses sociales más amplios.

Palabras clave: democracia - políticas públicas Estado - sociedad civil - América Latina

\begin{abstract}
Facing sociopolitical governance models, currently in vogue in Latin America, the article proposes to look back to the traditional political arena. Based on the analytical distinction between State, civil society and political society, made by Touraine, it deals with the relationship between democracy and public policy, distinguishing between different forms of participation of social and political actors. In Latin America, the most unequal
\end{abstract}


region in the world, democracy can only be social. The struggle for democratic demands is always possible and if it strengthens enough social movements, community groups and new social subjects, can change the balance of power in certain areas of public policy in favor of broader social interests.

Keywords: democracy - public policy - State - civil society - Latin America

\section{Introducción}

Volver al río turbio de la política para intentar desenturbiarlo un poco, tal fue la tesis central de un trabajo anterior (Canto 2012) en el que desarrollamos una crítica a los modelos de gobernanza sociopolítica de matriz liberal, hoy en boga en América Latina, por sus implicaciones potencialmente adversas para la democracia como, por ejemplo, la falta de núcleos mayoritarios de la población en las redes de actores y la ausencia de políticas públicas redistributivas en su agenda. La conclusión principal del artículo fue que fortalecer la democracia pasa por el perfeccionamiento de la política, antes que por su evasión hacia las redes de gobernanza.

Este trabajo es un intento de profundizar en las implicaciones de tal conclusión. ¿Qué puede significar volver la mirada hacia la política y por qué habríamos de hacerlo? Antes aún, ¿qué estamos entendiendo por política y también por democracia? Ambos términos tienen multitud de usos y, si no definimos con claridad el sentido en que los empleamos, las interpretaciones erróneas serán inevitables. En el caso de la democracia, por ejemplo, al lado de los conceptos clásicos de democracia representativa y directa hoy se habla de democracia participativa, que algunos consideran incluso más eficaz o más auténticamente democrática que la primera.

Algo que parece claro es cierto descrédito que pesa sobre diversos actores de la arena política tradicional, como los partidos políticos, los políticos profesionales e incluso algunos depositarios de los poderes constituidos, como los legisladores. El descrédito se extiende en algún grado al propio régimen democrático, y la democracia representativa suele ser descalificada como mecanismo de agregación, atención y respuesta eficaz a los problemas sociales y a las demandas ciudadanas. Este trabajo asume la tarea de argumentar a favor de la arena política tradicional, de los partidos políticos, de los poderes constituidos y de la propia democracia representativa; esto es, argumentar a favor del perfeccionamiento de la política 
La arena política tradicional se conceptualiza de manera precisa a partir de la propuesta teórica de Alan Touraine (2006) que distingue entre Estado, sociedad civil, y sociedad política. La distinción analítica entre Estado y sociedad política o sistema político es esclarecedora y útil para el propósito de argumentar a favor del perfeccionamiento de la política y, asimismo, para ubicar y entender mejor los términos de un debate que hoy tiende a oponer diversas formas de participación social y ciudadana a la democracia representativa.

Este trabajo tiene un segundo propósito, igualmente importante: aportar elementos para el análisis del nexo entre la democracia y las políticas públicas. Como no podía ser menos, el análisis de políticas en América Latina se ha orientado fuertemente a la acción, lo que desde luego se explica por el imperativo de atender los grandes problemas públicos de la región. Sin embargo, la atención a los problemas prácticos tal vez no ha dejado espacio suficiente para la reflexión más profunda sobre la vida política en nuestros países, y se percibe una distancia más o menos amplia entre los habituales métodos y técnicas del análisis de políticas, empleados por muchos de nuestros especialistas, y tópicos centrales en la agenda política de la región, como la profundización de la democracia y la promoción de la igualdad.

Temas como la relación entre el proceso de las políticas públicas y la vida democrática e institucional en nuestros países, las diferencias en contenidos y alcances entre los distintos tipos de políticas, o la participación social y ciudadana en el proceso de las políticas, son áreas que requieren de mayor elaboración teórica. En cuanto a la igualdad, los países latinoamericanos no han hecho bien la tarea, y América Latina sigue siendo la región más desigual del mundo; más desigual aún que África Subsahariana o Asia Meridional, por ejemplo (Palma 2011); la contribución de las políticas públicas a la reducción de la desigualdad y la pobreza es algo que en principio todo el mundo espera y que por lo mismo está (o debería estarlo) en la cima de la agenda de las políticas públicas. Sin embargo, el problema está en los cómos.

¿La mayor eficacia en el combate a la desigualdad está asociada a la participación directa de la ciudadanía en todo el proceso de las políticas públicas? ¿Qué tan amplia es, o puede llegar a ser esta participación y cómo puede impulsarse? ¿Cuál debe ser el papel y qué podemos esperar de los partidos políticos, los movimientos sociales o las organizaciones de la sociedad civil? ¿Qué podemos esperar también de los mecanismos de representación institucional, como las diputaciones o legislaturas, o de una amplia variedad de nuevos mecanismos de representación social que han surgido en varios países latinoamericanos, como los concejos de salud y educación, o los presupuestos participativos? ¿Cómo traducir y agregar las reivindicaciones locales en grandes reivindicaciones nacionales y en políticas de Estado? Este trabajo es un intento de aportar elementos para la reflexión sobre algunos de estos temas. En el primer apartado se reseña el marco teó- 
rico utilizado, que es la citada propuesta analítica de Touraine; en el segundo se aborda la relación entre democracia, participación y políticas públicas a partir de tres conjuntos de variables: los actores sociales y políticos; las modalidades de participación y los tipos de políticas en juego; el último apartado sintetiza las principales conclusiones.

\section{Estado, sociedad civil y sociedad política}

Touraine plantea que la democracia, como régimen político, requiere distinguir entre Estado, sociedad civil y sociedad política; esta última suele ser obviada en la clásica dicotomía Estado/sociedad civil, lo que se explica en parte por el hecho verificable de que la sociedad política difiere mucho en su grado de desarrollo entre las distintas sociedades, pudiendo en el límite no existir, como ocurre en los Estados totalitarios. Si la sociedad política -o sistema político, como también se le llama- se confunde con el Estado, encontraremos una subordinación directa de la multiplicidad de los intereses sociales a la lógica y la acción estatales, y en tales casos el horizonte más probable será el autoritarismo; a la inversa, si la sociedad política se funde con la sociedad civil, el orden político y jurídico tenderá a reproducir los intereses económicos dominantes. En ambos supuestos la gran perdedora será la democracia.

Así, la democracia se define por la autonomía de la sociedad política frente al Estado y a la sociedad civil, y por la mediación que ejerce entre ambos. Cuando la sociedad política no existe o es muy débil, asistimos al enfrentamiento directo entre el Estado y la sociedad civil, que probablemente conducirá a la victoria de uno o de otra, pero no a la democracia. La sociedad política es, entonces, el lugar por excelencia, el locus o el espacio de la democracia. Siguiendo a Touraine, y sólo como hipótesis de trabajo, podemos describir brevemente las tres entidades en estos términos:

Estado: es el conjunto de poderes que aseguran y defienden la unidad de la sociedad nacional frente a las amenazas y los problemas, tanto internos como externos, y es garante de su continuidad histórica; tiene la responsabilidad de defender la memoria colectiva y el largo plazo frente a la inmediatez; de garantizar el orden jurídico; de proteger a las minorías o grupos vulnerables de la sociedad y de alentar la creación cultural, aun si ésta no corresponde a las demandas del gran público. El Estado es más que el Poder Ejecutivo: es el conjunto de las administraciones públicas que aseguran éstas y muchas otras funciones, así como la planificación de largo plazo. Como observa Touraine, ninguna de estas funciones tiene como requisito esencial la democracia, y todas ellas son características de la mayoría de los Estados modernos, sean o no democráticos.

Sociedad civil: no es sólo el conjunto de intereses económicos; es el dominio de los actores sociales que se orientan a la vez por valores culturales y por relaciones a menudo conflictivas; es también el espacio de los particulares y sus mundos privados, de los gru- 
pos de interés de todo tipo, de los movimientos sociales y de las organizaciones e instituciones más diversas. En el juego infinito de intereses, muchas veces contrapuestos, los actores y movimientos sociales que animan a la sociedad civil no actúan naturalmente de manera democrática, aunque sólo la representación de sus intereses permitirá hablar de un sistema político democrático. Aquí es preciso recordar que el reconocimiento de la autonomía de la sociedad civil es la condición primera de la democracia moderna, y es precisamente la separación entre Estado y sociedad civil la que hace posible el surgimiento de la sociedad política o sistema político, de manera que, al final, es la sociedad civil la que legitima la acción del Estado.

Sociedad política o sistema político: A partir de la diversidad elabora la unidad, subordinando a ésta las relaciones de fuerza que existen en el plano de la sociedad civil y reconociendo el papel de los partidos políticos que se interponen entre los grupos de interés y el Estado. En una democracia corresponde al sistema político hacer y modificar la ley a través de los representantes electos, por tanto el Parlamento o Poder Legislativo es parte de él, aun si formalmente se le define como parte del Estado ${ }^{2}$. La separación de la sociedad política frente al Estado y la sociedad civil obliga a definir al orden político como una mediación entre ambos. En palabras de Kelsen, es la "formación de la voluntad estatal directriz mediante un órgano colegiado elegido por el pueblo y que toma sus decisiones por mayoría" (Touraine 2006: 64). Los representantes o diputados, entonces, no solamente representan a sus circunscripciones, electores o grupos de interés; son, aún más, los representantes de la nación y los hacedores de las leyes que se aplican en todo el territorio nacional.

Conforme a este esquema, la democracia sólo existe si se reconocen las lógicas propias, distintas y a menudo opuestas del Estado y la sociedad civil y si existe un sistema político autónomo frente a ambos. Cuando el sistema político es frágil, como por ejemplo en la Rusia postsoviética o en varios países de América Latina, la democracia es también frágil o de plano inexistente; una consecuencia común, en tales situaciones, es la falta de representación de los intereses de la sociedad civil y, en casos extremos, su total avasallamiento por el poder del Estado. No hay democracia donde reina el Estado absoluto, como tampoco la hay sin ley de la mayoría basada en la soberanía popular y si la democracia misma no se define como la manera política de asignar el poder, lo que sitúa a la política por encima de las actividades y los intereses particulares.

La democracia, entonces, sustituye la original lógica descendente de la soberanía, que va del Estado a la sociedad política y luego a la sociedad civil, por una lógica que va de abajo hacia arriba: de la sociedad civil al sistema político y de ahí al Estado, lo que no equivale a despojar de su autonomía ni al sistema político ni al Estado mismo. Un gobierno que estuviera al servicio directo de la opinión pública tendría efectos deplorables para la democracia. 
El sistema político tiene como tarea central hacer funcionar a la sociedad en su conjunto combinando la pluralidad de los intereses con la unidad de la ley, y sólo será democrático si a la vez que representa la unidad de los intereses nacionales representa asimismo los intereses de los actores sociales; es esta doble representación la que justifica la intervención de las democracias contemporáneas en la protección de las minorías, la redistribución de la riqueza y en general las intervenciones "voluntaristas" del Estado, empujado por fuerzas sociales, pero con la intermediación del sistema político, para promover objetivos de libertad, igualdad y justicia.

En oposición al marco liberal clásico, Touraine plantea que la democracia moderna ha de ser "social", en el doble sentido de, por una parte, promover el ejercicio de los derechos políticos de toda la población con medidas redistributivas de la riqueza y el poder y, por la otra, de brindar representación política a la pluralidad de intereses de la sociedad, incluidos los movimientos sociales y lo que este autor denomina nuevos sujetos sociales, que son grupos en situación de vulnerabilidad o marginación que logran organizarse políticamente para la defensa de sus intereses. Este modelo de democracia contrasta notablemente con el modelo original de democracia liberal, que reservaba a la población el único derecho de elegir a la élite que habría de gobernarlo, sin que el grupo gobernante estuviera obligado a asumir tales o cuales demandas de grupos, movimientos o clases provenientes de la base social. ${ }^{3}$

El esquema propuesto por Touraine no excluye la posibilidad de que el sistema político desborde los límites de la democracia y, en vez del riesgo de ser absorbido por el Estado o la sociedad civil, acabe absorbiendo a uno, a la otra o incluso a ambos. En la actualidad el riesgo más grande en este sentido es la llamada partidocracia, que tiene lugar cuando los partidos políticos dejan de estar sometidos a las demandas de los actores sociales y pierden su representatividad; en tal situación, pueden inclinarse del lado del Estado y destruir así la primera condición de existencia de la democracia, que es la limitación del poder estatal; pero pueden liberarse a la vez del Estado y de la sociedad civil y no tener ya otro fin que el crecimiento de su propio poder.

La corrupción más peligrosa para la democracia es la que permite a los partidos acumular recursos económicos tan considerables y tan independientes de la contribución voluntaria de sus miembros que les posibilitan escoger a los candidatos a puestos de elección popular y asegurar el éxito de cierto número de ellos, tornando irrelevante el principio de la libre elección de los dirigentes por los dirigidos. Que no hay democracia sin partidos políticos es algo que hoy pocos discuten, pero es cierto que la partidocracia destruye a la democracia al eliminar su representatividad, y conduce a la dominación de hecho de grupos económicos o de corrientes políticas. 
Pero hay otros peligros para la democracia asociados a un sistema político que invade a las otras esferas y vulnera su autonomía, ya sea al Estado, a la sociedad civil o a ambos. Touraine señala que las democracias parlamentarias europeas condujeron a veces al debilitamiento y a la descomposición del Estado, como muestra el ejemplo paradigmático de Italia. Otro caso es la invasión de la sociedad civil por los partidos, como ha ocurrido en países de América Latina donde la acción colectiva fue reducida a mero recurso político utilizado por los partidos y sus dirigentes. En este caso, el ejemplo paradigmático que menciona Touraine es el PRI mexicano, que durante más de la mitad del siglo XX gobernó directamente los sindicatos obreros y campesinos y las organizaciones urbanas. El corporativismo de Mussolini, Franco o Salazar y los Soviets leninistas son otras manifestaciones del desequilibrio de la relación entre las tres dimensiones o de la pérdida de autonomía de alguna de ellas; en todos los casos citados, la primera víctima fue la democracia.

\section{Democracia, participación y políticas públicas}

Si hablamos de políticas públicas, disciplina que no pocos de sus cultivadores consideran un campo de especialistas situado más allá de las cuestiones políticas, ¿por qué hablar de democracia? En todo caso, se acepta que las políticas públicas serán más eficaces y legítimas si cuentan con una amplia participación social o ciudadana en su diseño, implementación y evaluación. ¿No es suficiente con esto? Probablemente no.

Por principio de cuentas, la participación de los actores sociales, aunque deseable y muchas veces imprescindible, no siempre es sinónimo de democracia. En todas las sociedades, los grupos dominantes y las élites se cuentan entre los actores más participativos en los asuntos públicos, y con frecuencia su participación es más eficaz que otras gracias al empleo de medios que tienen en abundancia, como riqueza, poder y recursos de variados tipos, por ejemplo los medios masivos de comunicación. Así, es posible pensar en una participativa red de actores a cargo de un servicio público que ha sido privatizado y por tanto sustraído al debate democrático, como las telecomunicaciones o el espectro electromagnético, por ejemplo (Canto 2012).

¿Y por qué la democracia? Bueno, porque desde la Grecia clásica sabemos que es más seguro vivir en una sociedad en que los individuos tienen participación en el gobierno, así sea la participación infinitesimal del voto, que donde tal participación no existe y los ciudadanos quedan a expensas de la voluntad de otros, como ocurre en las dictaduras y las oligarquías, aun si son o pretenden ser benevolentes. Como se sabe desde la antigüedad, a un monarca justo y sabio puede sucederle un déspota, y una generación de burócratas sensatos puede ser relevada por una oligarquía depredadora y rapaz; en ausencia de democracia tales desgracias serán inevitables. La democracia no es el mejor de los sistemas políticos, tan sólo es el menos malo, como solía decir Winston Churchill. ${ }^{4}$ 
Pero, por todo lo dicho hasta ahora, democracia no significa el gobierno directo de la sociedad civil. La conversión no mediada por el sistema político de las demandas sociales en políticas públicas probablemente significará, en muchos casos, la entronización de los intereses dominantes, especialmente en aquellas áreas de la política pública que atañen a la distribución de la riqueza y el poder, o políticas redistributivas. Así, una sociedad con aspiraciones democráticas deberá distinguir con claridad entre democracia y participación; ésta es deseable y, como se ha dicho, a veces imprescindible, pero en ocasiones entrará en conflicto con la democracia.

Por lo demás, en el mundo contemporáneo sólo podemos hablar de democracia social, como dice Touraine, y esto es especialmente cierto en América Latina; la desigualdad y la pobreza extremas son enemigos mortales de la democracia, como bien sabemos en esta región con su larga estela de dictaduras o de populismos que preludiaron dictaduras. Pero sucede que los objetivos de redistribución social suelen ser impopulares entre los participativos grupos dominantes y las élites de nuestros países, que los perciben como amenazas a su riqueza o su poder. Entonces, el reto nada sencillo de nuestras democracias es diseñar e implementar políticas públicas fuertemente redistributivas sin salirse del marco democrático ${ }^{5}$.

Podemos volver ahora a la relación entre democracia, participación y políticas públicas. De lo dicho hasta ahora podemos subrayar varios puntos: si entendemos la democracia como un sistema de representación política de los intereses de los actores sociales y su conversión mediada por el sistema político en decisiones públicas o, en los términos ya citados de Kelsen, como la "formación de la voluntad estatal directriz mediante un órgano colegiado elegido por el pueblo y que toma sus decisiones por mayoría”, deberemos aceptar que no todas las modalidades de participación de los actores sociales son democráticas, lo que de ningún modo equivale a decir que sean ilegítimas o incluso prescindibles, pero es preciso distinguir claramente entre unas y otras.

De esto último se deriva otra distinción importante: el locus o espacio de la participación -democrática o no- de los actores sociales; ésta podrá darse ya en el seno de la sociedad civil, por ejemplo en redes interorganizacionales autoorganizadas de actores (Rhodes 1996; Kooiman et al. 2008), o bien en el marco de la sociedad política, mediante la participación de los actores en asociaciones políticas o partidos políticos, o simplemente con el ejercicio del voto en elecciones libres, lo que llamaremos participación democrática; desde luego, un mismo actor podría participar en ambas esferas, por ejemplo una asociación de industriales que promueve la innovación tecnológica en su territorio (participación en la sociedad civil) pero a la vez está integrada a un partido político (participación en la sociedad política por canales democráticos) y simultáneamente presiona al gobierno con limitar sus inversiones de no conseguir tal o cual objetivo de política económica (participación no democrática) ${ }^{6}$. 
Los actores políticos, siguiendo a Touraine, son los integrantes del sistema político o sociedad política: señaladamente los partidos políticos y, muy importante, los congresistas o representantes de la ciudadanía en el Poder Legislativo. Por su derecho al voto podemos considerar también al ciudadano de a pie como un actor político, si bien con un poder infinitesimal. Los actores políticos son los responsables de hacer y modificar la ley y definir el marco de actuación del Estado. Son, en tal sentido, actores protagónicos en un régimen democrático, aunque no necesariamente los más poderosos.

Por último, e igualmente importante para nuestro análisis, deberemos distinguir entre tipos de políticas públicas, dadas las profundas diferencias que pueden apreciarse entre unas y otras en términos de sus contenidos, alcances e implicaciones para la vida democrática de una nación. Con base en la sencilla pero todavía muy útil clasificación de Löwi distinguiremos entre políticas distributivas, regulatorias y redistributivas. Las primeras se caracterizan por su facilidad para agregarse y repartirse en unidades independientes entre sí. Los favorecidos y desfavorecidos no se enfrentan directamente; en muchas ocasiones los desfavorecidos no pueden siquiera identificarse como grupo. Las políticas regulatorias también causan impactos específicos e individuales, pero no pueden desagregarse; las leyes se elaboran en términos generales, sin embargo su impacto incide en elevación de costos y/o en reducción de opciones individuales; involucran una elección directa sobre quién se verá afectado y quién beneficiado en el corto plazo. Finalmente, las políticas redistributivas son similares a las regulatorias en el sentido de que incluyen relaciones entre amplias categorías de individuos, cercanas a considerarse como clases sociales (propietarios y desposeídos), e implican modificaciones de fondos en los acuerdos nacionales básicos, como la distribución de la riqueza y el poder. (Löwi 1992)

Tenemos así tres conjuntos de variables a considerar en nuestro análisis: los actores sociales y políticos, las modalidades de participación y los tipos de políticas públicas en juego. La lista de los actores no es exhaustiva y se reduce a los más significativos para nuestro análisis: los actores de la sociedad civil considerados son las agrupaciones ciudadanas y comunitarias, los movimientos sociales, las organizaciones de la sociedad civil (OSC), los grupos de interés económico y los poderes fácticos; de la sociedad política sólo consideramos a los partidos políticos y a los representantes electos; el Estado es abordado como un actor unitario. En lo que sigue del artículo abordaremos estas interrelaciones, tomando como eje central al conjunto de los actores.

\section{Sociedad Civil}

Agrupaciones ciudadanas y comunitarias. Los vecinos, ciudadanos y comunidades organizadas para alcanzar determinados objetivos son una modalidad creciente de participación en y desde la sociedad civil. América Latina cuenta con diversas experiencias de participación ciudadana y comunitaria en la prestación de servicios públicos, la elaboración de presupuestos, la planeación urbana y las políticas sociales. En Brasil, por ejemplo, la 
constitución de 1988 incluyó un código de ciudadanía que institucionalizó la descentralización y la participación ciudadana en la formulación e implementación de políticas sociales, al tiempo que fortaleció sensiblemente a los gobiernos municipales. En materia de salubridad se han instituido concejos de salud a nivel local. En el sector educativo se han creado concejos de educación a nivel estatal y también a nivel local, en cada escuela (Farah y Spink 2004).

En materia de desarrollo urbano y vivienda han proliferado las iniciativas basadas en la ayuda mutua, que involucran a la comunidad en el diseño, ejecución y monitoreo de proyectos urbanos y de vivienda. Brasil también registra experiencias de participación ciudadana en materia de presupuestos, como el programa de presupuesto participativo desarrollado en Porto Alegre, Río Grande Do Sul, que ha sido adoptado por gobiernos municipales en todo el país. En los términos de este programa, una parte del presupuesto municipal es discutido con la comunidad, que así participa en la definición de prioridades en la asignación de recursos.

Otras experiencias exitosas de participación ciudadana en América Latina se registran en Villa El Salvador, Perú; Tijuana, México; Montevideo, Uruguay y Rosario, Argentina; todas ellas orientadas a la construcción de un marco participativo en la planeación del desarrollo urbano; también destaca el ejemplo de Curitiba, en Brasil, en el rediseño y mejoras del sistema de transporte a partir de mecanismos de participación ciudadana (Cabrero 2005).

En general hay consenso en que estas modalidades de participación contribuyen al diseño, implementación y evaluación de políticas públicas más eficientes, eficaces y legítimas y que, por lo mismo, merecen y requieren el resuelto apoyo gubernamental. Por otro lado, como se desprende de los ejemplos citados, es posible distinguir entre formas de participación que se limitan a la arena de la sociedad civil, como los fondos de ayuda mutua, y otras que alcanzan cierto grado de institucionalización, como los concejos locales de salud y educación o los presupuestos participativos, promovidos y reconocidos por el gobierno brasileño y otros gobiernos latinoamericanos.

En este segundo caso podemos hablar, conforme a nuestro esquema, de un tipo básico de participación política e incluso de una forma elemental de democracia directa, al tener los ciudadanos el poder de decidir cómo se invierte una parte del presupuesto público. Sin embargo, salvo probables excepciones, en general las agrupaciones ciudadanas y comunitarias limitan sus demandas al ámbito de los servicios públicos y las políticas sociales, esto es, al campo de las políticas distributivas y quizá, a algunas regulatorias; las políticas redistributivas del poder y la riqueza, en cambio, suelen quedar más allá del alcance de sus reivindicaciones y de sus posibilidades de acción. 
Movimientos sociales. Son, siguiendo a Touraine, acciones colectivas que apuntan a modificar el modo de utilización social de recursos importantes en nombre de orientaciones culturales aceptadas en la sociedad considerada; tal fue el caso del movimiento obrero al conquistar una legislación laboral que limitó el poder avasallante del capitalismo. Un movimiento social ha de tener un programa político porque apela a principios generales, al mismo tiempo que a intereses particulares; otros ejemplos son los movimientos por los derechos civiles, los de equidad de género y los ecologistas. Los movimientos sociales y la democracia son indisociables en el mundo contemporáneo: si un sistema político los considera como expresión de demandas imposibles de satisfacer, pierde su representatividad y la confianza de sus electores. De hecho es únicamente en las sociedades democráticas donde prosperan los movimientos sociales (Touraine 2006: 87-90).

Un sistema político será tanto más democrático cuanto más represente las demandas de los movimientos sociales, las articule y las traduzca en políticas públicas que, en muchos casos, serán ciertamente redistributivas del poder y la riqueza, como fue el caso del movimiento obrero y lo es hoy de los movimientos de género o de los pueblos originarios, por ejemplo. Las demandas de los movimientos sociales interpelan directamente a los congresistas y también a los partidos políticos, intermediarios por excelencia entre las demandas sociales y los hacedores de la ley. También interpelan, desde luego, al poder Ejecutivo.

En el mismo sentido, el fortalecimiento de la democracia pasa por la construcción de nuevos sujetos sociales, definida como la conquista de la capacidad de expresión y de iniciativa de quienes deben ser reconocidos como actores sociales; es el caso de minorías oprimidas o marginadas como los inmigrantes, los homosexuales, las minorías étnicas o las religiosas. Touraine reconoce que esta capacidad, en sí misma una ampliación del campo político, no se obtiene mediante la mera reflexión, y sólo será posible por la acción de los propios interesados. Desde luego, una vez más, el apoyo de los partidos y de otros actores políticos, así como de organizaciones de la sociedad civil, suele ser de gran ayuda en la tarea nunca fácil de construir nuevos sujetos sociales.

Organizaciones de la sociedad civil (OSC). Como su nombre lo indica, surgen en la sociedad civil pero sus acciones con frecuencia desbordan a ésta para proyectarse sobre la arena política e incluso sobre el Estado, por ejemplo con los modernos sistemas de entrega de servicios públicos que las emplean como distribuidoras. Las hay de todos tipos, misiones, objetivos e ideologías, y su creciente número es también visto como un indicador del fortalecimiento, tanto de la sociedad civil como del sistema político y de la democracia misma.

El apoyo de las OSC a las reivindicaciones ciudadanas y comunitarias, así como a los movimientos sociales, es de la mayor importancia y a veces es incluso decisivo. En pa- 
labras de Harriss (2001), la realización del potencial comunitario de desarrollo requiere de la participación de las organizaciones no gubernamentales (otro nombre de las OSC) que aporten lo que el Banco Mundial llama capital social de puente, por ejemplo las redes de comercio justo, las asesorías de todo tipo o la capacitación en diversos campos del saber. El capital social de puente se da en las relaciones asimétricas entre personas con muy pocas características comunes, limitado contacto personal y generalmente con significativas diferencias en la posesión de recursos (Vallaeys 2008).

Sin embargo es preciso distinguir entre la participación de las OSC y la de los grupos comunitarios o los movimientos sociales, porque nunca son sinónimos. El citado Harriss y sus colegas distinguen entre asociación civil (los que trabajan para otros, como las OSC) y asociación social (los que trabajan por y para ellos mismos, como los grupos comunitarios). Según estos autores, Brasil en efecto tiene una de las sociedades civiles mejor organizadas en América Latina, pero con fuerte liderazgo de ONG antes que de ciudadanías locales, lo que hace una diferencia apreciable (Houtzager et al. 2002). Desde luego, la construcción de sujetos sociales, en tanto sólo puede ser obra de los propios sujetos sociales, no deberá confundirse nunca con la actividad de las OSC.

Grupos de interés económico. Son característicos de las economías competitivas de mercado, y en general representan los intereses de los inversionistas o de los propietarios de los medios de producción: organismos empresariales, asociaciones de productores, sindicatos patronales, entre otros. Su disponibilidad de recursos, comparativamente mayor a las de otros actores sociales, los convierte en actores de influencia también comparativamente mayor. A la vez, el liderazgo que ejercen en la vida económica de sus países los convierte en actores imprescindibles en el proceso de diseño e implementación de la política económica.

La participación -y, con frecuencia, el liderazgo- de los grupos de interés económico en redes de cooperación para el desarrollo territorial los convierte en actores centrales en las políticas de fomento a la productividad, la innovación y la competitividad. Frente a las dudas que genera la idea de cooperación entre competidores por antonomasia o, más aún, la posibilidad de que puedan conciliar sus intereses con otros actores del territorio (gobierno, sindicatos, ambientalistas) para construir metas comunes, se ha argumentado de modo convincente que sí es posible la cooperación en tales redes a partir del concepto de dependencia recíproca o interdependencia, desarrollado por Dirk Mesner: los actores particulares no tienen todo lo que necesitan para alcanzar los resultados a que aspiran, puesto que los recursos económicos, políticos, científico-tecnológicos, morales, están dispersos entre muchos actores. Las redes son patrones de organización que procesan la dependencia recíproca y superan la autorreferencialidad de los actores (Messner 1997, citado en Aguilar 2006: 125). 
Sin duda es así, y probablemente no exista alternativa al papel que desempeñan los grupos de interés económico cuando se trata, por ejemplo, de promover el desarrollo económico territorial en el marco de una economía competitiva de mercado, o en temas relacionados como la prestación de más y mejores servicios públicos. En cambio, cuando se trata de políticas redistributivas de la riqueza y el poder, como ampliar la participación del trabajo en el producto nacional o aumentar los impuestos para financiar un mayor gasto social, la historia suele ser diferente; en tales casos será mucho más probable encontrar resistencia que apoyo de parte de estos grupos (Canto 2012).

En todo caso, podemos ubicar a los grupos de interés económico entre los actores más participativos de un territorio, participación que suele extenderse a las tres dimensiones consideradas: a través de las ya citadas redes de actores en el marco de la sociedad civil; a través, en ocasiones, de su participación discreta o abierta en algún partido político, e incluso en el marco del Estado, por ejemplo mediante contratos para la prestación de los más variados servicios públicos y otros mecanismos semejantes, propios de la llamada Nueva Gestión Pública. Conforme a nuestro esquema, podemos distinguir también entre participación democrática de los grupos de interés económico, mediante el empleo de los canales institucionales de representación política, y participación no democrática, con el empleo de sus amplios recursos para presionar a las agencias públicas en busca de tales o cuales objetivos de política pública.

Poderes fácticos. Una buena idea de qué son los poderes fácticos es la desarrollada por Pablo González Casanova en La Democracia en México (1975), obra en que los llama factores de poder. Si bien la lista puede variar de un país a otro y de una época a otra, los poderes fácticos habitualmente incluyen a las grandes empresas nacionales y transnacionales y a los mayores grupos de interés económico; sin embargo no se limitan al ámbito económico y entre ellos debe incluirse también a la Iglesia, a los gobiernos de las mayores potencias extranjeras, a las instituciones financieras internacionales y a los medios de comunicación masiva, entre otros actores.

Aunque difícil de ubicar y evaluar, la influencia de los poderes fácticos en la política pública es innegable. Charles Lindblom y Robert Dahl, por ejemplo, sostienen que en las democracias liberales los poderosos intereses privados y mediáticos ejercen la influencia predominante en las decisiones públicas y distorsionan la agenda política, de tal manera que temas como la distribución del ingreso, la riqueza y el poder político o las prerrogativas empresariales -lo que Lindblom llama "las grandes cuestiones relativas a la estructura fundamental de la vida política y económica"- simplemente no se incluyen en la agenda (Dahl 1991, Lindblom 1999).

Podemos acaso dudar en llamar participación a la influencia de los poderes fácticos en la política pública; en cambio no podemos dudar que esta influencia o participación no es 
democrática y, en más de un sentido, puede considerarse contraria a la democracia, por cuanto distorsiona, como dice Lindblom, la agenda política construida por los canales institucionales y la deliberación abierta entre los actores sociales para inclinarla en la dirección deseada por poderosos y con frecuencia soterrados intereses privados y mediáticos. Un reto mayor de las democracias contemporáneas es contrarrestar o al menos moderar el peso de los poderes fácticos y evitar que su influencia excesiva limite o incluso paralice la acción del Estado en determinadas áreas de la política pública. Entre las maneras de enfrentar este reto y a la vez afirmar la democracia, una clara posibilidad es apoyar el fortalecimiento de los actores, movimientos y nuevos sujetos sociales, cuyos intereses se oponen a los intereses de los poderes fácticos en áreas específicas de la política pública.

\section{Sociedad Política}

Partidos políticos. Los partidos políticos han sido siempre actores polémicos. Desde la aparición de los primeros partidos modernos, en el siglo XIX, han sido vistos con recelo y desconfianza, ya fuera como potenciales disgregadores de la unidad nacional o como facciones movidas por intereses particulares y de grupo; y es que, como escribe Sartori, la palabra misma partido es ambivalente y hace referencia tanto a parte (de un todo) como a partición (división en fracciones). Sólo después de que se institucionalizaron los sistemas políticos nacidos de las revoluciones inglesa, estadounidense y francesa, las originales facciones prerrevolucionarias cedieron gradualmente el paso a los modernos partidos políticos en tales países y posteriormente en otros. (Sartori 2000: 17 y ss.)

El camino hacia el reconocimiento de los partidos como sujetos de derecho público ha sido largo y todavía no concluye. Hasta bien entrado el siglo XX siguieron siendo simples asociaciones privadas no reconocidas en las constituciones, y sólo después de la segunda guerra mundial lograron ser aceptados como sujetos de derecho público en Francia y Alemania y después en otras naciones. A finales del siglo XX, en la mayoría de los países los partidos políticos seguían siendo asociaciones privadas (Sartori 2000: 34).

En la actualidad es difícil encontrar un sistema político en que los partidos disfruten de la confianza de sus ciudadanías y no enfrenten algún grado de descrédito. Las causas de este descrédito son muchas y, entre otras, pueden mencionarse los frecuentes escándalos de corrupción asociados a las subvenciones que reciben de actores privados o empresas públicas, su paulatina conversión al modelo denominado catch all, o de maximización de votos al margen de ideologías, membresías y programas - lo que los convierte en poco más que empresas de mercadotecnia política-, y su desentendimiento de los problemas reales de política pública, asociado a la notable incompetencia de sus dirigencias para aportar respuestas y soluciones a los problemas y demandas de las ciudadanías. 
Y sin embargo los partidos políticos siguen siendo indispensables para la democracia. La alternativa a los partidos, cuando se ha ensayado, ha resultado peor y a veces desastrosa para el sistema político en cuestión: por ejemplo cuando un gran empresario o un grupo de interés económico han arribado al poder al margen de los partidos reconocidos como tales, con frecuencia ostentándose como no políticos que sin embargo hacen política, una contradicción que generalmente conduce a la entronización de intereses muy específicos. El ejemplo clásico de tal situación fue el italiano Silvio Berlusconi, poderoso empresario financiero y mediático que creó Forza Italia, un partido-empresa que apoyó su candidatura a la presidencia del Consejo de Ministros de su país (Vallès 2003: 349). Forza Italia demuestra que la alternativa más viable al partido político será el partido empresa, un cambio nada envidiable en una democracia.

Entre las funciones que siguen desempeñando los partidos y que resultan indispensables para la democracia podemos incluir la agregación y articulación de las preferencias electorales de los ciudadanos; la conversión de las demandas sociales en proyectos de ley, a cargo de los legisladores - normalmente, miembros reconocidos de partidos- o bien en programas de política pública a cargo de gobiernos subnacionales y nacionales y, no menos importante, el reclutamiento y formación de cuadros políticos que eventualmente ocuparán posiciones en las instituciones del Estado (Vallès 2003).

Más allá del descrédito generalizado que afecta a los partidos -que, además, suele ser amplificado por los poderosos intereses mediáticos de los que habla Lindblom- vale la pena recordar la definición clásica de partido político, formulada hace más de dos siglos por el político británico Edmund Burke y todavía vigente: “Un partido es un cuerpo de hombres unidos para promover, mediante su labor conjunta, el interés nacional sobre la base de algún principio particular acerca del cual todos están de acuerdo... Los fines requieren medios, y los partidos son los medios adecuados para permitir a esos hombres poner en ejecución sus planes comunes, con todo el poder y toda la autoridad del Estado" (Burke 1770, citado en Sartori 2000: 26)

El elemento central de la definición de Burke es el interés nacional, a ser promovido por un grupo de hombres unidos sobre la base de algún principio particular acerca del cual todos están de acuerdo. Al margen de los muchos y con frecuencia graves defectos de los partidos realmente existentes, es este compromiso de fondo con el interés nacional lo que distingue a los partidos políticos de los grupos de interés de todo tipo y que les brinda una base de legitimidad imposible de alcanzar por los partidos empresa, las redes de gobernanza, los líderes carismáticos o cualesquiera otras entidades que aspiren hoy a sustituirlos. En una democracia, desde luego, corresponde a los votantes decidir qué tan real es este compromiso con el interés nacional declarado por tal o cual partido. ${ }^{7}$ 
Volviendo a nuestro esquema, los partidos políticos son, junto con los legisladores, piezas fundamentales del sistema político y actores protagónicos de una democracia. Su sola existencia y participación en elecciones libres y competitivas constituyen elementos definitorios de un régimen democrático, tanto como su eliminación o la anulación de sus posibilidades de acceso al poder, ya sea de jure o de facto, definen a un régimen dictatorial. Cuando los partidos son proscritos o sólo existe un gran partido del Estado, como en algunas dictaduras contemporáneas, estamos en el supuesto descrito por Touraine (ver supra): la sociedad política ha perdido su eficacia o, en el límite, ha dejado de existir, para ser sustituida ya sea por el poder ilimitado del Estado, como sucedía con los regímenes del socialismo pro-soviético del siglo XX, o bien por una dictadura de derecha, habitualmente militar, que en la práctica significaba la entronización sin más de los poderes fácticos.

Como se ha señalado, corresponde a los partidos articular y agregar las demandas provenientes de la sociedad civil en anteproyectos de ley o de política pública, no sólo en la dimensión local o provincial sino también -y esto es muy importante- en la dimensión nacional; esta última, normalmente, queda fuera de las posibilidades de acción de los grupos comunitarios y ciudadanos, que tienen en los partidos afines a sus demandas una vía acaso insustituible en la actualidad para impulsar sus reivindicaciones más allá del plano local y proyectarlas al debate político nacional ${ }^{8}$. En una democracia los partidos son, entonces, intermediarios imprescindibles entre la sociedad civil y el Estado y - otro punto importante- sus reivindicaciones se extienden al conjunto de todas las políticas públicas para incluir demandas sociales de redistribución de la riqueza y el poder, al lado de demandas de mejores servicios públicos, de políticas sociales eficaces o de todo tipo de políticas regulatorias.

La otra cara de la moneda es el espectro siempre presente de la partidocracia, de la que habla Touraine, que se materializa cuando los partidos políticos dejan de estar sometidos a las demandas de los actores sociales y pierden su representatividad, para ya no tener otro fin que el crecimiento de su propio poder. Es éste un riesgo muy real de las democracias contemporáneas, ejemplo característico de la pérdida del equilibrio en las relaciones entre sociedad civil, sociedad política y Estado, que es tan importante como la autonomía de cada esfera. Al igual que en el caso de la limitación del poder del Estado, el acotamiento del poder de los partidos políticos y su sometimiento al orden constitucional es tarea indelegable de una sociedad civil participativa y actuante, sin que haya sustituto conocido para esa responsabilidad.

El riesgo de la partidocracia aumenta considerablemente con la falta de control de las aportaciones de grupos privados a los partidos políticos, ya sean abiertas, cuando la ley no las ha limitado, o encubiertas, como suelen darse en la mayoría de los casos. Adam Przeworski afirma que, para la ciudadanía de a pie, dichas aportaciones sin control son 
peores que el robo abierto, porque en los hechos se traducirán en privilegios y prebendas todavía más jugosas para los interesados donadores que los montos aportados, en detrimento del resto de la sociedad (Przeworski 1998: 362). ${ }^{9}$ Las subvenciones legales a los partidos con cargo al erario público, no siempre bien comprendidas por los ciudadanos -o desacreditadas por los también interesados medios masivos de comunicación-, son así fundamentales para el fortalecimiento de la democracia porque, sumadas a las limitaciones legales a las aportaciones privadas, contribuyen a nivelar las condiciones de las contiendas electorales.

Representantes electos. Las democracias modernas son esencialmente representativas y los ensayos de democracia directa, cuando tienen lugar, son generalmente de limitado alcance -frecuentemente acotados al ámbito de lo local- y suelen enfocarse en la prestación de servicios públicos o en determinadas políticas distributivas. Las políticas redistributivas y la mayoría de las regulatorias, como se ha dicho, trascienden con mucho las posibilidades de los actores locales y normalmente se definen en el ámbito de los gobiernos nacionales.

Los representantes electos por la ciudadanía al Congreso, Parlamento o Dieta -entre otros nombres que el Legislativo recibe en los distintos países- forman parte, en nuestro esquema, de la sociedad política, por cuanto fungen como intermediarios entre la sociedad civil y el Estado. Una pregunta, que sigue siendo motivo de un debate no concluido, es a quién o a quiénes representan realmente los congresistas, y la respuesta incluye al menos tres posibles sujetos: a los votantes del distrito que los eligió, al interés nacional o al partido político al que pertenecen.

Si la respuesta fuera sólo a los electores de su distrito, los legisladores quedarían reducidos al papel de voceros de la sociedad civil, y en tal caso no se justificaría considerarlos como intermediarios entre ésta y el Estado, antes bien seguiríamos en la clásica dicotomía Estado/sociedad civil; por otro lado, si sólo representasen al interés nacional -al margen de lo que se entendiese por esto- estaríamos en el modelo de la democracia liberal original, que reserva a los ciudadanos el único derecho de elegir a los que habrán de gobernarlos, sin mayor responsabilidad de los elegidos por representar los intereses de sus electores. Por último, si los congresistas sólo representasen a los partidos políticos a los que pertenecen, estaríamos en el supuesto de una sociedad política que se representa a sí misma, algo inadmisible en una democracia, y desde luego también estaríamos en la antesala de la partidocracia.

Una posible respuesta es que los legisladores representan a los tres sujetos a la vez. En una democracia los congresistas representan los intereses de sus electores y esta representación es irrenunciable; como se ha señalado, la democracia se fortalece con el acceso a la representación política de grupos sociales cada vez más amplios: comunidades 
organizadas, movimientos sociales y nuevos sujetos sociales, al dar presencia y voz en el gobierno nacional a reivindicaciones que el tradicional balance de poder mantiene en la penumbra o en el silencio. Pero, al mismo tiempo, se espera que los congresistas miren más allá de los intereses de sus distritos para representar simultáneamente al interés general de la nación y hacer o modificar las leyes que imperan en todo el territorio nacional.

La identificación de los congresistas con las directrices de sus partidos es un tema un tanto más complejo. Al criticar esta identificación, Touraine recuerda que la opinión pública emite un juicio desfavorable sobre los personajes políticos que aparecen como defensores de intereses particulares, y sostiene: "Cuando un partido político, como los Verdes en Alemania, reduce de manera extrema la autonomía de sus elegidos, dándoles mandatos imperativos que hacen de ellos delegados más que representantes, e impone una rotación rápida de la labor parlamentaria entre los elegidos de una lista, demuestra sobre todo su incapacidad para transformar un movimiento social en fuerza política..." (Touraine 2006: 66).

Sin embargo, parece claro que cierto grado de disciplina partidaria también resulta un ingrediente necesario en una democracia; por una parte, es la afinidad ideológica de los congresistas de un partido, como decía Burke, lo que permite sumar los votos necesarios para impulsar determinadas leyes o reformas; por otro lado, como recuerda Vallès, "allí donde -como es el caso de Estados Unidos- es poca o inexistente la disciplina de partido, existe el riesgo de que cada parlamentario se convierta en rehén de los intereses del grupo económico o social con cuyo apoyo financiero y electoral ha obtenido su escaño. Es pública, a este respecto, la influencia que ejercen sobre el voto de determinados parlamentarios las grandes empresas, los colectivos profesionales, algunos sindicatos, sectas religiosas, asociaciones racistas o grupos defensores de la libre venta de armas. La libertad respecto del partido se convierte en dependencia respecto de grupos de presión económica" (Vallès 2003: 214).

Lo que señala Vallès, visto en los términos de nuestro esquema, es la pérdida del equilibrio entre sociedad política y sociedad civil, con el resultado público y notorio -como señala este autor- del sometimiento del parlamento a las demandas no mediadas de la sociedad civil. Los representantes de los intereses de las compañías tabacaleras o de los grandes bancos en el Congreso estadounidense demuestran que los partidos políticos, en el sentido que los definió Burke, son también piezas esenciales del sistema político. Existe desde luego el riesgo que Touraine ejemplifica con el caso de los Verdes en Alemania pero, como él mismo afirma, los partidos que se exceden en este sentido pagan la factura en las elecciones. 


\section{Estado}

De acuerdo con nuestro esquema, la democracia supone relaciones equilibradas entre sociedad civil, sociedad política y Estado, y también la autonomía de cada uno. Como se ha comentado, la democracia se debilita, al punto de desaparecer, cuando una de las tres entidades invade el espacio de las otras. Esto ocurre, por ejemplo, cuando el Estado avasalla a la sociedad civil o a la sociedad política, y en tal caso hablamos de autoritarismo, dictadura o incluso totalitarismo. Pero también opera contra la democracia el fenómeno opuesto: un Estado tan débil que termina sometiéndose a los dictados de la sociedad civil - con toda probabilidad, a los dictados de los grupos dominantes de la sociedad civil-, o bien del sistema político, como en el citado caso del parlamentarismo italiano. Así pues, al lado de la autonomía y el equilibrio, también es condición de la democracia un Estado fuerte, desde luego sumado a una sociedad política fuerte y una sociedad civil fuerte también. La fortaleza de las tres entidades es, a fin de cuentas, la fortaleza de la democracia.

Antes de continuar vale la pena recordar, con Przeworski, que el Estado rige; esto es, dicta $y$ obliga, y que la democracia, en el sentido más amplio, es una forma de ser gobernado; no es, ni puede ser, una alternativa a ser gobernado. Incluso en una democracia directa, continúa este autor, las decisiones de la mayoría son valederas para todos, aun para la minoría que considera que van en contra de su opinión o intereses. En una democracia representativa "estas decisiones son tomadas e instrumentadas por representantes electos así como por funcionarios designados a quienes los representantes delegan algunas de las tareas de gobernar. Los representantes deciden lo que los ciudadanos deben hacer, y obligan a los ciudadanos a acatar sus decisiones" (Przeworski 1998: 342).

¿Significan las fuertes palabras de Przeworski que el Estado es de suyo una dictadura? Por supuesto que no. La democracia es aquel régimen en que las grandes decisiones se toman por mayoría y todos los ciudadanos tienen la oportunidad de participar en el gobierno, ya sea de manera directa o a través de sus representantes pero, como dice este autor, una vez tomada la decisión ésta es vinculante, es decir, obligatoria para todos, incluso para los que se opusieron a ella. Ahora bien, el contenido de las decisiones vinculantes será más democrático en tanto represente intereses más amplios de la ciudadanía, y lo será menos cuando tiendan a prevalecer los intereses de las élites o las oligarquías, como ocurre en las actuales democracias latinoamericanas. (Nun 2002, Touraine 2006)

Volviendo a nuestro esquema y de acuerdo con nuestra definición operativa del Estado, los actores centrales del mismo son, en primer lugar, el titular -o titulares, en su casodel Poder Ejecutivo, seguido por el conjunto de las administraciones públicas. Las principales funciones del Estado, según nuestra definición operativa, incluyen asegurar la unidad y la continuidad histórica de la nación, defender la memoria colectiva, garantizar el orden jurídico, planificar a largo plazo, proteger a las minorías o grupos vulnerables 
de la sociedad y alentar la creación cultural. Naturalmente, en una sociedad democrática el Estado también deberá contar entre sus principales funciones la garantía, protección y fortalecimiento del orden democrático.

Recordemos que la democracia se fortalece con la mayor igualdad socioeconómica de los ciudadanos y se debilita con su mayor desigualdad, porque esta última significa una menor o incluso nula capacidad de ejercer sus derechos civiles, políticos y sociales para los ciudadanos más empobrecidos, que en algunos de nuestros países llegan a ser mayoría. Si el Estado cuenta entre sus responsabilidades garantizar y fortalecer el orden democrático, podemos esperar que incluya entre sus prioridades un resuelto combate a la desigualdad, cuya reducción permitirá incrementar el ejercicio de los derechos ciudadanos y asegurar una representación más amplia de los intereses sociales como base de la acción del propio Estado. En el plano de las ideas y las declaraciones existe un relativo consenso en torno al papel del Estado como promotor activo de la democracia mediante el empoderamiento de sus ciudadanías. Sin embargo, como decíamos al principio, el problema está en los cómos.

Si la desigualdad social predomina, escribe Przeworski, el poder estará distribuido de manera desigual e inevitablemente debilitará las perspectivas de que todos disfruten por completo los derechos civiles y políticos; por ejemplo, la tributación es más difícil en las sociedades más desiguales, y las razones que explican esto son más políticas que económicas: los ricos tienen más poder sobre el gobierno en las sociedades más desiguales y los pobres tienen menor capacidad de utilizar sus derechos democráticos. Los ricos encuentran que es más eficaz contratar servicios varios de manera privada-educación, salud, seguridad- que pagar impuestos que mantendrían estos servicios para todos. Los pobres están justo al margen del Estado: no tienen ingresos para ser gravados y reciben pocos servicios. De aquí surge un círculo vicioso: los pobres son ineficaces políticamente puesto que no disfrutan de las condiciones necesarias para el ejercicio eficaz de sus derechos políticos; y como son ineficaces, continúan siendo pobres (Przeworski 1998).

¿Cómo romper este círculo vicioso? Algo que parece claro es que el modelo liberal de democracia, que enfatiza la libertad negativa (Berlin 1974) y confia en las fuerzas del mercado para alcanzar el desarrollo y reducir la desigualdad, es insuficiente en América Latina. En palabras de Touraine, en los países en desarrollo una política puramente liberal no puede producir más que efectos contrarios a la democracia, porque deja en la exclusión a una parte importante de los individuos que, sin embargo, querrían participar como consumidores y ciudadanos en la vida social.

El modelo liberal de democracia implica otro riesgo para los países latinoamericanos: no sólo no resuelve el problema de la desigualdad en la región -la peor del mundo, no lo olvidemos- sino que provoca el desencanto de nuestras ciudadanías ante la demo- 
cracia $^{10}$. No es muy difícil explicar tal desencanto. A propósito de la experiencia argentina, José Nun describe un fenómeno "bastante peculiar que se ha vuelto distintivo del área: la baja o nula asociación positiva que se detecta entre la protección social y la democracia representativa (...) A diferencia de lo sucedido en las naciones capitalistas avanzadas, la protección social creció aquí en ausencia parcial o total de la democracia representativa y, a la inversa, tendió a descender precisamente cuando se afirmaba esta última" (Nun 2002: 170).

Lo que describe este autor es un hándicap terrible para la democracia en América Latina, sin duda. Pero, ¿de qué democracia estamos hablando? El mismo Nun responde: en América Latina ha prevalecido el modelo schumpeteriano o minimalista de democracia, que es básicamente el modelo liberal de democracia en el sentido aquí planteado: los electores seleccionan a quienes habrán de gobernarlos y nada más. Lo que los gobernantes hagan es decisión exclusiva de ellos y, en todo caso, si a los electores no les gusta lo que hace un equipo gobernante podrá cambiarlo por otro en las siguientes elecciones; la representación política de los intereses sociales y su conversión en leyes y políticas de Estado no es en sí una prioridad, o en todo caso tal conversión es una decisión unilateral de los gobernantes. Este modelo de democracia, que se desentiende de las desigualdades socioeconómicas y de la existencia de estratos, clases o diferencias sociales más o menos profundas en la sociedad, es por completo insuficiente en América Latina ${ }^{11}$.

Uno de los riesgos del desencanto de la democracia, en parte materializado ya en la región, es el retorno del populismo que, a diferencia de la democracia puramente liberal, sí puede mejorar la protección social y reducir la desigualdad. El citado Nun nos recuerda también que un régimen populista autoritario no es una democracia ni tampoco un estado de bienestar por el solo hecho de otorgar una serie de derechos sociales, mientras cercena los derechos civiles y políticos. El riesgo aumenta porque "históricamente forman legión los latinoamericanos que han visto sistemáticamente confiscada su autonomía por derecha o por izquierda. Baste pensar en los regímenes oligárquicos, en las dictaduras, en los populismos autoritarios o en los movimientos leninistas y similares", tal es la pesada tradición heterónoma en nuestra región (Nun 2002: 212). ${ }^{12}$

Frente a los pobres resultados de la democracia liberal en el plano social y los inaceptables costos políticos del populismo, sigue abierta la cuestión de cómo fortalecer y consolidar la democracia en América Latina o, en otros términos, como romper el círculo vicioso del que habla Przeworski. Algo que en principio parece evidente es que un gobierno que se limite a los estrechos marcos de la democracia liberal no llegará muy lejos en esta tarea y acabará perpetuando la desigualdad socioeconómica y política. Entonces, un deber de las democracias latinoamericanas, si aspiran a sobrevivir y consolidarse, es diseñar e implementar políticas públicas que apunten a la redistribución de la riqueza y el poder como base insustituible del desarrollo de ciudadanías fuertes y capaces de 
afirmar sus democracias (Forester 1992). Democracia y justicia redistributiva vienen a ser, a fin de cuentas, las dos caras de una misma moneda.

Sin embargo resta el problema planteado por Przeworski: los estados latinoamericanos suelen ser muy débiles para enfrentar el enorme poder de las oligarquías dominantes, y carecen del contrapeso de ciudadanías fuertes a causa de la agobiante pobreza y la desigualdad, que en la práctica impiden a grandes núcleos de la población el ejercicio eficaz de sus derechos políticos (el círculo vicioso en sí). Przeworski tiene razón, y el típico Estado latinoamericano no puede por sí solo romper el círculo. Para romperlo hace falta más que la sola acción del Estado. Una posibilidad de lograrlo es, en sí misma, la fórmula de la democracia asumida en este trabajo: un Estado fuerte, respaldado por una ciudadanía fuerte y con la intermediación de un sistema político fuerte también.

Una ciudadanía capaz de respaldar eficazmente políticas redistributivas de la riqueza y el poder implica el reto nada fácil de empoderar a los sujetos sociales de los que antes hablamos: movimientos sociales, grupos comunitarios y ciudadanos y nuevos sujetos sociales. No menos fácil, pero igualmente insoslayable, es el reto de consolidar sistemas políticos fuertes y autónomos, capaces de asegurar la auténtica representación política de los intereses mayoritarios de la base social.

En síntesis, si la democracia liberal es insuficiente en América Latina, la alternativa sólo puede ser la democracia social, impulsada por un Estado de Derecho promotor de la igualdad socioeconómica con capacidad de decisión suficiente, capaz de oponerse a los dictados de los grupos hegemónicos con el contrapeso de grupos sociales organizados. Es en este sentido que Touraine habla de intervenciones voluntaristas del Estado, empujado por las fuerzas sociales. Sin embargo, como reconoce este autor, la tarea más importante y dificil en América Latina es fortalecer actores sociales y políticos capaces de luchar contra las desigualdades que hacen imposibles la democracia y el desarrollo, y es ésta, a no dudarlo, la tarea principal de los partidarios de la democracia en la región.

\section{Comentarios finales}

Harold Lasswell llamó "ciencias de las políticas en la democracia" ${ }^{13}$ a la disciplina que él mismo fundó, poco después de la segunda guerra mundial, para mejorar el contenido y la racionalidad de las decisiones públicas. Sin embargo, no todos los cultivadores de la disciplina han compartido la preocupación de su fundador por la democracia, y diversos autores han llamado la atención sobre la "deriva tecnicista y práctica" (Mèny y Thoenig 1992) o la "insidiosa especialización técnica” (Ascher 1994) del análisis de políticas, no por el uso en sí de abundantes métodos cuantitativos y modelos econométricos -lo que es perfectamente explicable, dada la naturaleza de muchos problemas prácticos- sino 
por la creencia de que los complejos problemas públicos se pueden resolver con ese tipo de técnicas, al margen de la vida política y los valores democráticos.

Este trabajo partió del supuesto de que la democracia es importante y, más aún, es decisiva para el éxito de las políticas que atienden los grandes problemas socioeconómicos de una región como América Latina, donde prevalece una aguda desigualdad social. Como escribieron, con distintas palabras, varios de los autores citados en el texto, el fortalecimiento de la democracia y el combate a la desigualdad son las dos caras de una misma moneda y no es posible quedarse con sólo una de ellas: si queremos afirmar la democracia deberemos combatir la desigualdad, y viceversa, si queremos combatir la desigualdad deberemos afirmar la democracia.

También, por lo antes argumentado, no podemos quedarnos solamente con el modelo liberal de democracia, que reserva la toma de las decisiones públicas a los grupos gobernantes y deja a la sociedad la única decisión de seleccionar a la élite que habrá de gobernarla. Decir que la democracia en América Latina sólo puede ser social significa, en pocas palabras, asegurar la representación política de los intereses sociales mayoritarios y su conversión en políticas públicas y programas de gobierno.

El bosquejo aquí presentado de la relación entre democracia y políticas públicas aspira a ser de alguna utilidad en la promoción del binomio democracia-igualdad y, en particular, ha buscado perfilar algunas respuestas a cuestiones todavía imprecisas, como la relación entre participación y democracia, el papel de los principales actores sociales y políticos en el proceso de las políticas públicas y las relaciones entre sociedad civil, sistema político y Estado. Así, con base en lo expuesto en el artículo, podemos aventurar las siguientes afirmaciones:

La democracia implica siempre participación, pero no toda participación es democrática, y es necesario distinguir muy bien entre ambas para evitar errores de apreciación que pueden ser importantes. Ciertos tipos de participación al margen de los canales institucionales de representación política, especialmente de los poderosos intereses privados y mediáticos (Lindblom), no pueden considerarse democráticos, aunque esto no necesariamente significa que sean ilegales o incluso ilegítimos, pero no hay que confundir las cosas.

En el mismo sentido, ciertos mecanismos horizontales de participación de actores sociales, como las llamadas redes de gobernanza, pueden perseguir objetivos socialmente valiosos -como de hecho lo hacen-, por ejemplo promover el desarrollo económico territorial o la prestación de mejores servicios públicos, pero tal vez sea poco sensato pedirles que hagan suyos y promuevan objetivos fuertemente redistributivos de la riqueza 
y el poder, sobre todo cuando incluyen en sus filas a los propios beneficiarios del statu quo que sería afectado por políticas redistributivas que persigan combatir a fondo la desigualdad socioeconómica. También aquí, los errores de apreciación pueden ser costosos.

La participación de los grupos comunitarios y ciudadanos, fundamental para el éxito de numerosas políticas públicas - como ejemplifican las experiencias de Brasil y otros países latinoamericanos-, podría sin embargo no ser suficiente para impulsar con éxito reivindicaciones de alcance nacional, y en ese caso el papel de partidos políticos afines sería crucial para articular y agregar las demandas y convertirlas en propuestas de política pública a través de los representantes electos y los poderes constitucionales.

Los movimientos sociales, en el sentido aquí planteado, tienen un alcance mayor y, por lo menos algunos de ellos, sí pueden proyectar sus demandas en el plano nacional; como se ha dicho, la democracia misma se fortalece con la incorporación de las demandas de los movimientos sociales en la agenda nacional y su atención con políticas públicas y programas de gobierno. Por supuesto, los apoyos provenientes de las organizaciones de la sociedad civil, de los partidos políticos e incluso de representantes electos y dependencias públicas, pueden ser de gran valía para el logro de los objetivos de los movimientos sociales.

Las organizaciones de la sociedad civil tienen un lugar relevante en la vida democrática de nuestros países, toda vez que su papel como promotoras, educadoras e impulsoras de demandas provenientes de la base social es en varios sentidos insustituible y, por lo mismo, merecen el reconocimiento y el apoyo de los actores políticos y los gobiernos. Sin embargo, también aquí es preciso no confundir la acción de las OSC con la acción de los grupos comunitarios o los movimientos sociales, como señalan Harriss y sus colegas a propósito de la sociedad civil brasileña. Si la movilización de una comunidad se explica sobre todo por la acción de las OSC, el riesgo más evidente será el retraimiento o incluso el retiro de tales OSC, que podría significar el fin de la movilización; parece bastante claro que la acción independiente de los grupos ciudadanos y comunitarios a favor de sus demandas no tiene sustituto.

La construcción de nuevos sujetos sociales, acaso la tarea más ardua en las democracias latinoamericanas, puede requerir del concurso de las OSC, de otros grupos comunitarios y movimientos sociales, de partidos políticos afines, de funcionarios y oficinas públicas y de todos los actores sociales y políticos comprometidos con la democracia y dispuestos a apoyar la compleja y dificil tarea de procurar voz a quienes no la tienen; sin embargo, como en el caso anterior, será la acción reivindicatoria de los propios sujetos sociales la que los constituirá como tales; tampoco aquí caben sustitutos. 
La democracia y la igualdad, como binomio indisociable, requieren ciertamente del concurso de todos los actores sociales y políticos que se identifiquen con la tarea; ésta es demasiado grande y compleja para que pueda ser completada por unos pocos actores solamente. Los partidarios de la democracia y la igualdad bien pueden actuar desde abajo, apoyando la organización y las reivindicaciones de grupos comunitarios, movimientos sociales y nuevos sujetos sociales, y también desde arriba, impulsando desde los poderes constituidos el diseño e implementación de políticas fuertemente redistributivas de la riqueza y el poder.

Por lo demás, no es necesario negar la existencia de los grupos hegemónicos y los poderes fácticos para sostener que el poder del Estado no está fatal e irremediablemente al servicio de los poderosos intereses privados y mediáticos. La lucha por las reivindicaciones democráticas siempre es posible y, si logra fortalecer lo necesario a los grupos comunitarios y ciudadanos y a los movimientos y nuevos actores sociales, puede llegar a cambiar la correlación de fuerzas en determinadas áreas de la política pública en favor de intereses sociales más amplios. Se trata sin embargo de una lucha larga y dificil, a librar por caminos siempre nuevos. 
${ }^{1}$ El contenido de este apartado sigue el desarrollo de Touraine (2006) caps. III-VII.

${ }^{2} \mathrm{~A}$ la inversa, un jefe del Ejecutivo elegido por el voto popular tiene una representación democrática e incluso ciertas funciones legislativas; en este sentido es parte del sistema político; sin embargo, sus funciones centrales de ejecutar la ley y garantizar el orden político lo definen como parte esencial del Estado.

${ }^{3}$ Sin embargo, Touraine advierte que no debemos procurar nunca oponer enteramente liberalismo y democracia, porque es ésta quien sería la víctima principal de una oposición tan artificial (Touraine 2006: 78). En tal sentido podemos decir que la democracia social no es la negación, sino en todo caso la superación de la democracia liberal, al permitir y propiciar la representación de intereses sociales más amplios en las decisiones públicas.

${ }^{4}$ Vaya un dato para ilustrar este punto: Con abundante información empírica y elaborada estadística, Adam Przeworski y sus colegas han calculado que el solo tránsito de la dictadura a la democracia en una sociedad aumenta en más de una década la esperanza de vida de la población (Przeworski et al. 2000).

${ }^{5}$ Sacrificar la democracia en aras de la igualdad, como parecen dispuestas a hacer algunas corrientes políticas en América Latina, es del todo inaceptable. Podemos decir, con Hobsbawm y Valiani en Historia del Siglo XX: "Nuestro siglo demuestra que el triunfo de los ideales de la justicia y la igualdad siempre es efimero, pero también que, si conseguimos preservar la libertad, siempre es posible comenzar de nuevo." (Hobsbawm 1999: 12) ${ }^{6}$ Una vez más: no democrático no significa necesariamente ilegal, sino sólo que la participación de los actores no sigue los canales democráticos de agregación y representación de las demandas, que en una democracia constituyen el sistema político propiamente dicho: voto, elecciones, partidos y representantes electos. La participación no democrática de los actores más poderosos, sin duda la más eficaz, obra por supuesto en contra de la igualdad política, y en este sentido puede considerarse antidemocrática.

${ }^{7}$ El compromiso con el interés nacional "sobre la base de algún principio particular" permite establecer cierto paralelismo entre los partidos políticos y los movimientos sociales como los define, con un lenguaje diferente, Alain Touraine: acciones colectivas que apuntan a modificar el modo de utilización social de recursos importantes en nombre de orientaciones culturales aceptadas en la sociedad considerada. Un movimiento social apela a principios generales más allá de sus intereses particulares, como fue el caso del movimiento obrero al conquistar una legislación laboral que limitó el poder del capital y benefició a la mayoría de la población. ${ }^{8}$ Por contraste, los grandes grupos de interés económico y en general los poderes fácticos no requieren de los partidos políticos para acceder a las esferas de decisión, aunque también suelen emplearlos como medios para conseguir sus fines, como demuestran los escándalos de las aportaciones económicas fuera de todo marco legal hechas a los partidos por grandes intereses privados y mediáticos, que de vez en cuando trascienden a la opinión pública.

${ }^{9}$ Przeworski considera a esas aportaciones el mayor atentado contra la calidad de la democracia, porque convierte a la competencia electoral en algo así como un partido de básquetbol entre un equipo de jugadores de más de dos metros de alto y otro de jugadores bajitos "como yo" (Przeworski 2003: 26).

${ }^{10}$ Pueden verse, al respecto, los informes anuales de Latinobarómetro, que mide las opiniones de los ciudadanos sobre la democracia en países latinoamericanos.

${ }^{11}$ Recordemos algunos de los planteamientos centrales de Schumpeter al criticar lo que llama la teoría clásica de la democracia para proponer su otra teoría de la democracia: "Se recordará que nuestros problemas principales con la teoría clásica se centraban en la proposición de que "el pueblo" tenía una opinión definida y racional acerca de cada cuestión individual y que llevaba a la práctica esta opinión -en una democraciaeligiendo "representantes" encargados de vigilar la ejecución de la opinión. En esta forma, la selección de los representantes es algo secundario ante el propósito primario del arreglo democrático que es el de investir al electorado con el poder de decidir las cuestiones políticas. Supongamos que invertimos los papeles de estos dos elementos y hacemos que la decisión de las cuestiones por el electorado sea algo secundario ante la elección de los hombres que han de tomar las decisiones. En otras palabras, ahora adoptamos la opinión de que el papel del pueblo es la creación de un gobierno, o de un cuerpo intermedio que a su vez creará un ejecutivo o gobierno nacional.Y definimos: el método democrático es el acuerdo institucional para la toma de decisiones donde los individuos adquieren el poder de decisión mediante una lucha competitiva por el voto del pueblo" (Schumpeter 1974: 265). Esta idea de la democracia sería posteriormente desarrollada por otros economistas, como Downs (2001) y Niskanen (1980).

${ }^{12}$ En los términos de Berlin (1974) podríamos afirmar que los populismos, sobre todo en sus versiones más radicales, cercenan tanto la libertad negativa (derechos civiles) como la positiva (derechos políticos o igualdad 
política), ambas igualmente imprescindibles en un régimen democrático. Quizá el mayor agravio a las ciudadanías es el reemplazo de la autonomía por la heteronomía política, rasgo que comparten, como dice Nun, las dictaduras de izquierda con las de derecha.Y de la heteronomía política, como ya sabían los clásicos griegos, no podemos esperar nada bueno más allá del corto plazo.

13 “Policy sciences of democracy", fue la expresión acuñada por Lasswell (1992: 93).

\section{Referencias Bibliográficas}

Aguilar, Luis (2006) Gobernanza y Gestión Pública. México: Fondo de Cultura Económica.

Ascher, William (1994) "La evolución de las ciencias de políticas". En Luis Aguilar (comp.) El estudio de las políticas públicas. México: Miguel Ángel Porrúa: 181-195.

Berlin, Isaiah (1974) "Dos conceptos de la libertad". En Anthony Quinton (comp.) Filosofía Política. México: Fondo de Cultura Económica.

Cabrero, Enrique (2005) Acción pública y desarrollo local. México: Fondo de Cultura Económica.

Canto, Rodolfo (2012) “Gobernanza y democracia. De vuelta al río turbio de la política”. Gestión y Política Pública, vol. XXI, núm. 2, segundo semestre: 333-374.

Dahl, Robert (1991) Los dilemas del pluralismo democrático: Autonomía versus control. México: Alianza Editorial.

Downs, Anthony (2001) “Teoría económica de la acción política en una democracia”. En A. Batlle (ed.) Diez Textos Básicos de Ciencia Política. Barcelona:Ariel: 93-111.

Farah, Marta y Peter Spink (2004) “El programa brasileño de gestión pública y ciudadanía”. Gestión y Política Pública, vol. XIII, núm. 1, primer semestre: 209-236.

Forester, John (1992) "La racionalidad limitada y la política de salir del paso". En Luis Aguilar (comp.) La hechura de las políticas. México: Miguel Ángel Porrúa: 315-340.

González Casanova, Pablo (1975) La democracia en México. México: Ediciones Era.

Harriss, John (2001) "Social capital construction and the consolidation of civil society in rural areas". Working Paper Series 01-16. London: Development Studies Institute, LSE.

Hobsbawm, Eric (1999) Historia del Siglo XX. Buenos Aires: Grijalbo Mondadori. 
Houtzager, Peter et al. (2002) "Rights, representation and the poor: Comparisons across Latin America and India”. Working Paper Series 02-31. London: Development Studies Institute, LSE.

Kooiman, Jan et al. (2008) "Interactive Governance and Gobernability: An Introduction”. The Journal of Transdisciplinary Environmental Studies vol. 7, núm.1:1-11.

Lasswell, H. (1994) "La orientación hacia las políticas". En Luis Aguilar (comp.) El estudio de las políticas públicas. México: Miguel Ángel Porrúa: 79-103.

Lindblom, Charles (1999) Democracia y sistema de mercado. México: Fondo de Cultura Económica.

Lowi, Theodore (1992) "Políticas públicas, estudios de caso y teoría política". En Luis Aguilar (comp.) La hechura de las políticas. México: Miguel Ángel Porrúa: 89-117.

Mèny, Ives y Jean Claude Thoenig (1992) Las Políticas Públicas. Barcelona: Ariel.

Niskanen, William (1980) Cara y cruz de la burocracia. Madrid: Espasa-Calpe.

Nun, José (2002) Democracia: ¿Gobierno del pueblo o gobierno de los políticos? México: Fondo de Cultura Económica.

Palma, José Gabriel (2011) "Homogeneous middles vs. heterogeneous tails, and the end of the 'Inverted-U': the share of the rich is what it's all about". Cambridge Working Papers in Economics 1111, January.

Przeworski, Adam (1998) “El Estado y el ciudadano”. Política y Gobierno, vol.V, núm. 2, segundo semester: 341-379.

Przeworski, Adam (2003) “Capitalism, Democracy and Science”, Interview with Adam Przeworski, conducted and edited by G. L. Munck, February 24, New York: Mimeo

Przeworski, Adam et al. (2000) Democracy and Development: Political Institutions and Well-Being in the World, 1950-1990. New York: Cambridge University Press.

Rhodes, R. A. W. (1996) “The New Governance: Governing without Government”. Political Studies, vol. XLIV: 652-667.

Sartori, Giovanni (2000) Partidos y sistema de partidos, Madrid: Alianza Editorial. 
Schumpeter, Joseph (1974) "Dos conceptos de la democracia”. En Anthony Quinton (comp.) Filosofía Política. México: Fondo de Cultura Económica.

Touraine, Alan (2006) ¿Qué es la democracia? México: Fondo de Cultura Económica.

Vallaeys, François (2008) La Responsabilidad Social Universitaria como marco institucional para la innovación educativa. Mérida: Universidad Autónoma de Yucatán (mimeo).

Vallès, Josep (2003) Ciencia Política: una introducción. Barcelona: Ariel. 